[Bull. Agr. Chem. Soc. Japan, Vol. 24, No. 7, p. 716 718, 1960]

\title{
Studies on Phenolic Lactones
}

\section{Part V. General Route to Substituted $\beta$-Benzyl- $\gamma$-butyrolactones and an Alternate Synthesis of $( \pm)$ Hibalactone}

\author{
By Kyôhei Yamashita and Masanao Matsui \\ Faculty of Agriculture, University of Tokyo \\ Received June 13, 1960
}

\begin{abstract}
Substituted $\beta$-benzyl- $\gamma$-butyrolactones were synthesized. Hydrolysis and decarboxylation of ethyl $\alpha$-allyl- $\alpha$-benzyl malonate gave $\alpha$-allyl- $\alpha$-benzyl acetic acid. Esterification of the acid and subsequent reduction with lithium aluminum hydride afforded $\beta$-benzyl- $\beta$-allyl ethanol. Oxidation of the double bonds with potassium permanganate followed by periodate treatment, silver oxide oxidation and lactonization yielded $\beta$-benzyl butyrolactones. Thus $\beta$-benzyl-, $\beta$-piperonly-, $\beta$ 3,4,5-trimethoxybenzyl- butyrolactone were prepared.

Condensation of piperonal and $\beta$-piperonyl- $\gamma$-butyrolactone with sodium ethylate afforded $( \pm)$ hibalactone.
\end{abstract}

The authors were interested in preparing substituted $\beta$-benzyl- $\gamma$-butyrolactones as intermediates for further synthetic work. It is a well known fact that the condensation of substituted malonic esters with ethylene oxide or substituted $\beta$-benzyl butyrolactones.

The authors attempted several other routes for the synthesis of $\beta$-benzyl- $\gamma$-butyrolactones. For the first time the authors attempted the lactonization of $\gamma$-bromo butyronitriles as follows:

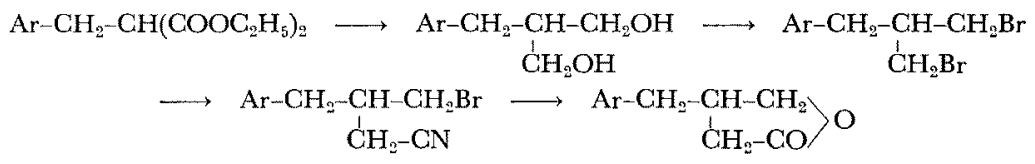

lactonization of $\gamma$-haloesters afford $\alpha$-benzyl- $\gamma$ butyrolactones. For the synthesis of substituted $\beta$-benzyl $-\gamma$-butyrolactones, however, only a few reports have appeared in the literature. Reduction of $\beta$-substituted succinic acid $\beta$-mono thioalkyl ester with Raney nickel catalyst ${ }^{13}$ or hydroxymethylation of $\beta$-benzoyl propionic acid followed by catalytic hydrogenation ${ }^{23}$ afford
But in the course of this route the reaction of one mole of sodium cyanide with one mole of dibromide afforded only a small amount of bromo-nitrile and the product was mainly dinitrile and recovered dibromide. Accordingly the yield of $\beta$-benzyl butyrolactone was very poor. So the authors devised an another scheme as follows:

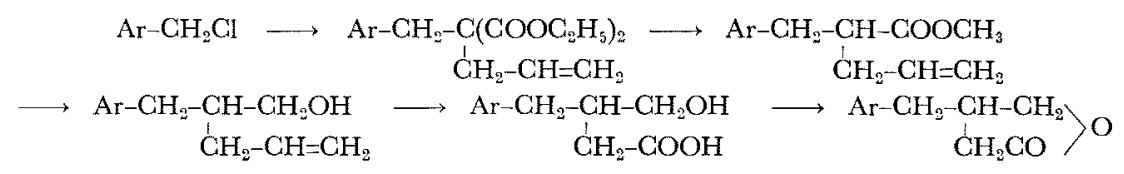

1) S. Okumura, M. Masumura, T. Horie and S. Kori, J. Soc Org. Synth. Chem. Japan, 17, 461 (1951).

2) J. Rothe and H. Zimmer, J. Org. Cbem. 24, 586 (1959).
Hydrolysis and decarboxylation of ethyl $\alpha$ allyl- $\alpha$-benzyl malonate gave $\alpha$-allyl- $\alpha$-benzyl 
acetic acid. Esterification of the acid and subsequent reduction with lithium aluminum hydride afforded $\beta$-benzyl- $\beta$-allyl ethanol. Oxidation of the double bonds with potassium permanganate followed by periodate treatment, silver oxide oxidation and lactonization yielded $\beta$-benzyl butyrolactones. Of course, the ozonization of $\beta$-allyl- $\beta$-benzyl-ethanol was expected to yield the same results.

For the synthesis of some of the substituted $\beta$-benzyl- $\gamma$-butyrolactone reduction of $\beta$-benzoyl$\gamma$-butyrolactones seemed to be superior method, however, $\beta$-piperonyl butyrolactone was more easily obtained by our method than that from $\beta$-piperonoyl butyrolactone.

The authors attempted the condensation of piperonal with $\beta$-piperonyl- $\gamma$-butyrolactone. Although the condensation of piperonal with $\beta$ piperonyl-butyrolactone by the use of potassium amide in liquid ammonia afforded hydroxylactone, the use of sodium ethylate or sodium hydride in benzene gave racemic hibalactone.

\section{EXPERIMENTAL}

\section{$\beta$-Benzyl- $\gamma$-butyrolactone (General procedure)}

a) Ethyl $\alpha$-allyl- $\alpha$-benzyl acetate

Ethyl allyl malonate $(50 \mathrm{~g}, 0.25$ mole) was alkylated with $35 \mathrm{~g}(0.28$ mole $)$ of benzyl chloride in the presence of $5.8 \mathrm{~g}(0.25 \mathrm{~mole})$ of sodium in absolute ethanol.

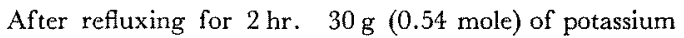
hydroxide in $100 \mathrm{ml}$ of water was added and refluxed for an hour to saponify the esters. After the distillation of alcohol neutral substances were removed by ether extraction. An aqueous solution was acidified with hydrochloric acid and extracted with ether. After the evaporation of the ether the residual mass was heated to $170 \sim 180^{\circ} \mathrm{C}$ to decarboxylation. The crude acid was esterified by refluxing with ethanol and sulfuric acid for $2 \mathrm{hr}$. The neutral fraction was separated and distilled in vacuo. Ethyl $\alpha$-allyl- $\alpha$-benzyl acetate was distilled at $120 \sim 125^{\circ} \mathrm{C}$, yielded $26.2 \mathrm{~g}$. Anal. Found: C, 77.32; H, 8.06. Calcd. for $\mathrm{C}_{14} \mathrm{H}_{18} \mathrm{O}_{2}$ : C, 77.1; $\mathrm{H}, 8.2 \%$.

\section{b) $\beta$-Allyl- $\beta$-benzyl ethanol}

Ethyl $\alpha$-allyl- $\alpha$-benzyl acetate, $26.2 \mathrm{~g}$ (0.12 mole), was reduced with $2.66 \mathrm{~g}$ ( 0.07 mole) of lithium aluminum

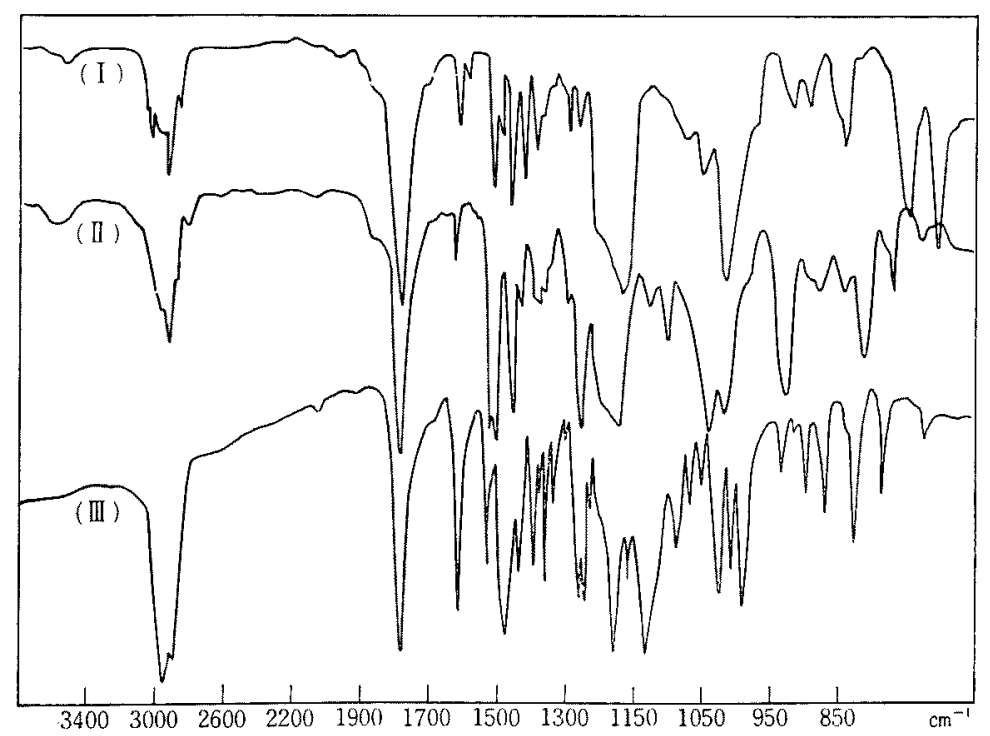

FIG. 1. Infrared Absorption Spectra of $\beta$-Benzyl- $\gamma$-butyrolactones.
(I) $\beta$-Benzyl- $\gamma$-butyrolactone (film)
(II) $\beta$-Piperonyl- $\gamma$-butyrolactone (film)
(III) $\beta \cdot 3,4,5$-Trimethoxybenzyl- $\gamma$-butyrolactone (Nujol muli) 
hydride. $\beta$-Allyl- $\beta$-benzyl ethanol was distilled at $120 \sim$ $121^{\circ} \mathrm{C} / 6 \mathrm{~mm}$, yielded $19.3 \mathrm{~g}$. Anal. Found: C, 82.20 ; $\mathrm{H}, 9.06$. Calcd. for $\mathrm{C}_{1 \mathrm{~s}} \mathrm{H}_{16} \mathrm{O}: \mathrm{C}, 81.8 ; \mathrm{H}, 9.1 \%$.

\section{c) $\beta$-Benzyl- $\gamma$-butyrolactone}

A solution of $17.4 \mathrm{~g}$ ( 0.11 mole) of potassium permanganate in $350 \mathrm{ml}$ of water was added to a cold solution of $19.3 \mathrm{~g}(0.11$ mole) of $\beta$-allyl- $\beta$-benzyl ethanol in $100 \mathrm{ml}$ of acetone at $0 \sim 5^{\circ} \mathrm{C}$. After stirring for $2 \mathrm{hr}$. below $10^{\circ} \mathrm{C}$ and then 1 hour at $60^{\circ} \mathrm{C}$, the reaction mixture was filtered to remove manganese dioxide. After the evaporation of acetone from the filtrate, $200 \mathrm{~g}$ of potassium carbonate was added. Crude triol was separated as a oily layer, weighted $16.9 \mathrm{~g}$.

Crude 2-benzyl pentanetriol $(1,4,5)$ was dissolved in $50 \mathrm{ml}$ of water and was added to a solution of $18.3 \mathrm{~g}$ ( 0.08 mole) of periodic acid in $100 \mathrm{ml}$ of water with stirring under cooling.

After stirring for an hour, the separated hydroxyaldehyde was extracted with ethyl acetate. Evaporation of the solvent from the extract left 13.8 of crude $\beta$ benzyl- $\gamma$-hydroxybutyraldehyde. The crude aldehyde in $50 \mathrm{ml}$ of warm ethanol was added to a suspension of silver oxide freshly prepared from $26.4 \mathrm{~g}$ of silver nitrate in $100 \mathrm{ml}$ of $5 \%$ sodium hydroxide solution and warmed for 30 minutes at $80^{\circ} \mathrm{C}$ with vigorous stirring. The hot mixture was filtered and ethanol was distilled off. After the removal of neutral substances with chloroform extraction the aqueous solution was acidified with hydrochloric acid and warmed on water bath for 30 minutes. The reaction mixture was extracted with chloroform, and the extract was washed with sodium bicarbonate solution and water. After removal of solvent, the residual mass was distilled in vacuo. $\beta$-Benzyl- $\gamma$-butyrolactone was distilled at $165 \sim 166^{\circ} \mathrm{C} / 6 \mathrm{~mm}$, weighed $6.4 \mathrm{~g}$. Anal. Found: $\mathrm{C}, 74.07$; $\mathrm{H}, 6.93$; Calcd. for $\mathrm{C}_{11} \mathrm{H}_{12} \mathrm{O}_{2}$ : C, $75.0 ; \mathrm{H}, 6.8 \%$. Infra-red spectrum showed a characteristic lactone band at $1740 \mathrm{~cm}^{-1}$.

\section{$\boldsymbol{\beta}$-Piperonyl- $\boldsymbol{\gamma}$-butyrolactone}

Methyl $\alpha$-allyl- $\alpha$-piperonyl acetate was prepared from $50 \mathrm{~g}$ of allyl malonate and $48 \mathrm{~g}$ of piperonyl chloride in the similar manner as described in general procedure. It was distilled at $188^{\circ} \mathrm{C} / 21 \mathrm{~mm}$, yielded $32 \mathrm{~g}$. Anal. Found: $\mathrm{C}, 67.81 ; \mathrm{H}, 7.18$. Calcd. for $\mathrm{C}_{14} \mathrm{H}_{18} \mathrm{O}_{4}: \mathrm{C}$, $67.8 ; \mathrm{H}, 6.4 \%$;.

$\beta$-Allyl- $\beta$-piperonyl ethanol, b.p. $190^{\circ} \mathrm{C} / 14 \mathrm{~mm}$, was obtained by lithium aluminum hydride reduction of the ester in 95\% yield. Anal. Found: C, 70.75; H, 7.84. Calcd. for $\mathrm{C}_{13} \mathrm{H}_{16} \mathrm{O}_{3}: \mathrm{C}, 70.9: \mathrm{H}, 7.3 \%$.

$\beta$-Piperonly- $\gamma$-butyrolactone was obtained by the general procedure, b.p. $174 \sim 175^{\circ} \mathrm{C} / 0.4 \mathrm{~mm}$, weighed $7.4 \mathrm{~g}$. Anal. Found: C, 64.91, H, 5.27. Calcd. for $\mathrm{C}_{12} \mathrm{H}_{12} \mathrm{O}_{4}: \mathrm{C}, 65.5 ; \mathrm{H}, 5.4 \%$.

\section{$\beta-3,4,5$-Trimethoxybenzyl- $\gamma$-butyrolactone}

Methyl $\alpha$-allyl- $\alpha$-(3,4,5-trimethoxybenzyl)-acetate was prepared by the general procedure, b. p. $180 \sim$ $183^{\circ} \mathrm{C} / 6 \mathrm{~mm}$.

$\beta$-Allyl- $\beta$-(3,4,5-trimethoxybenzyl)-ethanol, b.p. $188 \sim$ $189^{\circ} \mathrm{C} / 6 \mathrm{~mm}$, was prepared by the reduction of the ester in $92 \%$ yield. Anal. Found: $\mathrm{C}, 67.48 ; \mathrm{H}, 9.06$. Calcd. for $\mathrm{C}_{15} \mathrm{H}_{22} \mathrm{O}_{4}: \mathrm{C}, 67.7 ; \mathrm{H}, 8.3 \%$.

$\beta-(3,4,5$-Trimethoxybenzyl)- $\gamma$-butyrolactone was obtained by general procedure, b.p. $168 \sim 170^{\circ} \mathrm{C} / 0.1 \mathrm{~mm}$, m.p. $81 \sim 83^{\circ} \mathrm{C}$ (from methanol). Anal. Found: C, 63.04; $\mathrm{H}, 7.54$. Calcd. $\mathrm{C}_{14} \mathrm{H}_{18} \mathrm{O}_{5}: \mathrm{C}, 63.1 ; \mathrm{H}, 6.8 \%$.

\section{( \pm ) Hibalactone}

To a suspension of sodium ethylate prepared from $0.54 \mathrm{~g}$ of sodium in dry benzene, a solution of $4.0 \mathrm{~g}$ of $\beta$-piperonyl- $\gamma$-butyrolactone and $3.0 \mathrm{~g}$ of piperonal in benzene was added with external cooling. After stirring for $5 \mathrm{hr}$. at $0 \sim 5^{\circ} \mathrm{C}$ the reaction mixture was allowed to stand over night. After refluxing for $4 \mathrm{hr} .50 \mathrm{ml}$ of water was added and refluxed for an hour. After cooling the organic layer was discarded and the aqueous solution was acidified with hydrochloric acid and warmed on water bath for 30 minutes. The mixture was extracted with ethyl acetate and the extract was washed with dilute sodium bicarbonate solution and with water, and the ethyl acetate distilled off. The residue was recrystallized from methanol. The colorless plate, m.p. $153 \sim 155^{\circ} \mathrm{C}$, was obtained, weighed $1.0 \mathrm{~g}$. Upon admixture with authentic $( \pm)$ hibalactone the m.p. did not depressed. When sodium hydride was used instead of sodium ethylate, the same results were obtained.

Acknowledgements The authors are grateful to the members of the Analytical Laboratory of the Department of Agricultural Chemistry, University of Tokyo, for microanalytical data. They are also indebted to Mr. K. Aizawa for the measurement of infra-red spectrum. 